\title{
THERMAL PERFORMANCE OF SOLAR ENERGY STORAGE IN SOME SOLID MATERIALS
}

\author{
Gamea, G. R.* ; Taha, A. T.**; and Keshek, M. H***
}

\begin{abstract}
The study carried out, to study thermal performance of some solid as storage units. Three similar storage units were designed, manufactured and evaluated in Agricultural Engineering Department, Faculty of Agricultural, Minoufiya University. Three types of granulates are Basalt, Sand and Gravel were used to store solar energy during the day, at three thicknesses (20, 40 and $60 \mathrm{~cm}$ ). The all experiments carried out with closed units during daylight and opened in the night. The all experiments repeated with opened units during daylight and night. Thermal performance was evaluated by, hourly energy stored, daily energy stored $(\mathrm{KJ} / \mathrm{kg})$, storage thermal efficiency, and characteristics of passing air through storage units.

Basalt gave the best results in with all condition, the amount of hourly heat stored at Basalt at thickness $60 \mathrm{~cm}$.

The daily amount of heat $(\mathrm{kJ} / \mathrm{kg})$ stored in storage materials at thickness $20 \mathrm{~cm}$ was higher than at thicknesses 40 and $60 \mathrm{~cm}$.

The daily amount of heat stored in the Basalt was 23.98, 12.88 and 8.89 $\mathrm{kJ} / \mathrm{kg}$ at the thickness of 20,40, $60 \mathrm{~cm}$, respectively, when the storage units are closed during daylight. And by 5.64, 3.29 and $2.92 \mathrm{~kJ} / \mathrm{kg}$ at the thickness of 20,40, $60 \mathrm{~cm}$, respectively, when the storage units are open during daylight.
\end{abstract}

The mean storage efficiency for storage materials at thickness $60 \mathrm{~cm}$ was higher than at thicknesses 40 and $20 \mathrm{~cm}$.

The difference in air temperature at the entry and exit from the storage units was higher in the case of air passing through storage unit at $20 \mathrm{~cm}$ by 54.61, $77 \%$ than its at thicknesses were 40, $60 \mathrm{~cm}$, respectively, when the storage units are closed during the daylight and opened during night.

\footnotetext{
* Assoc Prof. of Agric. Eng. Dep., Fac. of Agr., Min. Univ.

** Lect. of Agric. Eng. Dep., Fac. of Agr., Min. Univ.

***Ass lect. of Agric. Eng. Dep., Fac. of Agr., Min. Univ.
} 


\section{INTRODUCTION}

The advantage of solar energy, and their applications in different agricultural fields are of great importance and a challenge to

1 researchers and scientific research, one of the main problems of use solar energy is that the sun be available in large quantities on the day and ends when the sun sets so you must store the solar energy during the day and then be re-used during the night.

Duansheng et al, (1991) studied experimentally the thermal efficiency of the walls of two different types of the greenhouses. The first type wall of the greenhouses was built by rammed earth with $0.50 \mathrm{~m}$ thickness and that of the second type of greenhouses held the vacancy interlayer brick wall, i.e. from inside room to outside room with brick of $0.12 \mathrm{~m}$, vacancy interlayer $0.12 \mathrm{~m}$ and 0.24 brick respectively.

instead of water, but additional collector area must be provided. Using a stratified air tank, the system efficiency can be increased by $5 \%$ and amount of heat stored by $25 \%$ over a day. The

use of water system was found superior from the heat capacity point of view, but there were problems in maintaining the system.

Johnson, (1992) cited thick section of 20-30 cm are used when the sun shines directly on the material, and thinner larger- area sections of 10-15 $\mathrm{cm}$ are used when the sunlight is diffused within a space where storage, and release occurs from the same surface.

El-Kassaby and Ghoneim (1993) Analyzed natural soil for air based system and water for water based system in the sensible heat storage systems to study the variations in the amount of energy stored with time. They reported that the use of soil as storage material is possible

Dincer and Dost (1996) Reported that a solar system designer must seek answers to some basic questions about energy storage before proceeding with a project, such as: 'What types of storage are available?' 'However much storage is required?' 'How will the inclusion of storage affect the system performance, reliability and cost?' 'What storage systems or designs are available? 
Hamdan, (1998) Cited that for many solar energy applications, water is used as a storage medium, however, for a solar collector which uses air as the working fluid, rock is the legitimate choice as a storage medium.

Ozturk and Bascetincelik (2003) reported that the solid materials were economically more attractive for high temperature heat storage than fluids and their volume requirements were nearly comparable. Direct contact between the solid storage medium and heat transfer fluid was vital to minimize the cost of heat exchange in a sensible heat storage system. The charging and discharging process of a thermal energy storage system was recommended to be analyzed in order to optimize the system efficiency.

The choice of storage medium is often influenced by the working fluid in a solar heating system. Thus, if air is the heat transfer fluid used in a solar system, then a rock bed thermal storage is an obvious choice (Duffie and Beckman, 2006). If the primary working fluid is a liquid, then a liquid is usually used as a storage medium. It has been noted that water is an excellent storage medium for the low-to-medium temperature range because of its high volumetric heat capacity, low cost and widespread availability.

El-Sebaii, et al. (2007) concluded that the thermal efficiency of solar collector with gravel is found to be higher than that without the packed bed by $22-27 \%$. Gravel as a packed bed above the absorber plate during low intensity solar radiation periods is recommended.

Gil et al. (2010) cited that sensible thermal energy storage (TES) consists of a storage medium, a container (commonly tank) and inlet/outlet devices. Tanks must both retain the storage material and prevent losses of thermal energy. The existence of a thermal gradient across storage is desirable. Sensible heat storage can be made by solid media or liquid media. Solid media (for the temperature range studied in this paper, mainly high temperature concrete and castable ceramics) are usually used in packed beds, requiring a fluid to exchange heat. When the fluid is a liquid, heat capacity of the solid in the packed bed is not negligible, and the system is called dual storage system. Packed beds favour thermal stratification, which has advantages. An advantage of a dual system is the 
use of inexpensive solids such as rock, sand or concrete for storage materials.

Therefore the present research was conducted with study the thermal performance of three different materials to store solar energy (Basalt Gravel and Sand) at three thicknesses (20,40 and 60) to select the best material and the thickness should be use.

\section{MATERIALS AND METHODS.}

Three identical storage units were designed and manufactured in the Faculty of Agricultural., Menoufiya University and installed on the roof of Agricultural Engineering Department at latitude $\left(30^{\circ}\right)$.

\section{MATERIALS:-}

\section{Storage units:-}

The Storage units were made of having initial dimensions of $1.0 \mathrm{~m}$ long, $0.70 \mathrm{~m}$ wide and deep at three depths $(22.5,42.5$ and $62.5 \mathrm{~cm})$ as shown in figure (1). The walls and bottom was constructed of two layer of plywood (0.003 m thickness) and the space between the two layer are insulated by foam layer $(0.03 \mathrm{~m}$ thickness $)$, and the tope of each unit covered with glass ( $3 \mathrm{~mm}$ thick) and the unit tilted at an angle of $30^{\circ}$ which is the optimum slope angle at noon according to (Abdellatif, 1985), and leave a space between the glass cover and storage material of $2.5 \mathrm{~cm}$ so that the thickness of the storage material becomes $(20,40$, $60 \mathrm{~cm})$. And placed in the middle of the wooden box six tubes buried in the middle of the storage material as shown in figure (2) $(5.2 \mathrm{~cm}$ diameter and $100 \mathrm{~cm}$ length) made of steel.

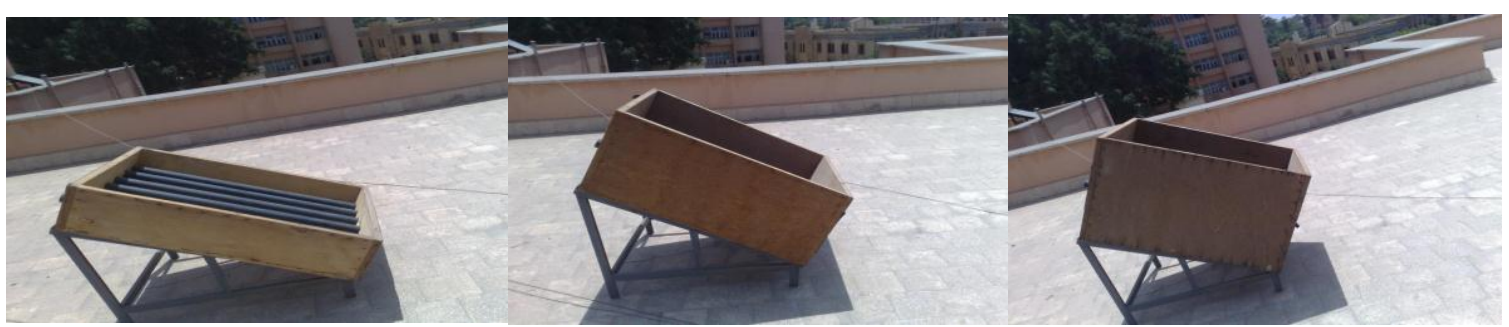

Th $20 \mathrm{~cm}$

Th $40 \mathrm{~cm}$

Th $60 \mathrm{~cm}$

Fig. (1): Storage units. 

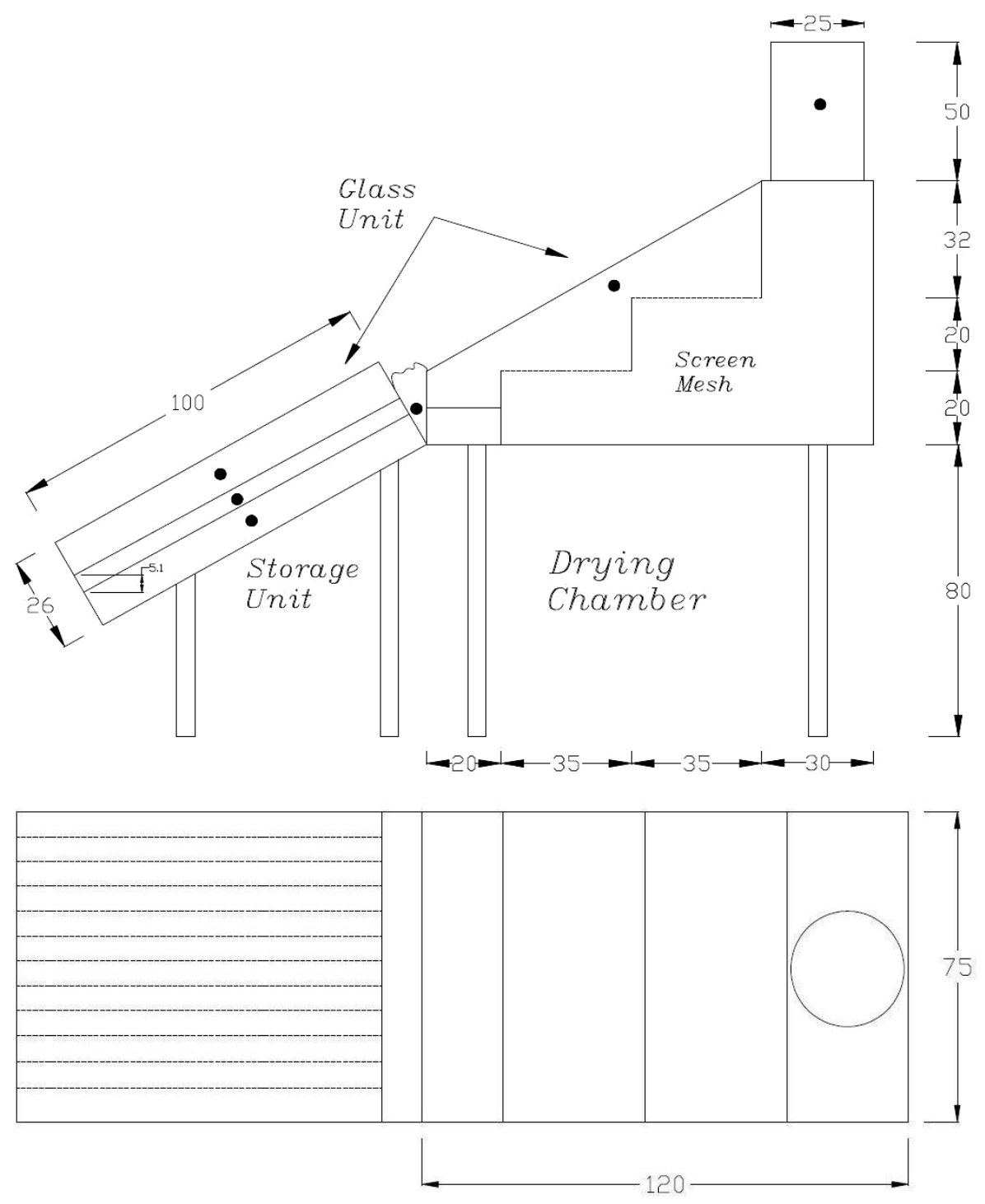

Fig. (2): Schematic diagram of air passing through storage unit (Dim. In $\mathrm{cm})$, .Temperature measuring points.

Extracting fan:- An extracting fan of $0.25 \mathrm{~m}$ diameter (Sonya, mode 20wuc) 220-240 volts (50 Hertz) made in Egypt. Was functioned in the experimental work.

\section{Storage materials:-}

Three types of granulates was used as a storage materials are (Basalt, Sand, and Gravel) shown in. the thermal properties shown in the table (1):- 
Table (1):Thermal properties of (Basalt - Gravel- Sand). Somerton (1992), Dincer and Rosen (2010),

\begin{tabular}{|c|c|c|c|c|}
\hline Material & $\begin{array}{c}\text { Density, } \\
\text { (p) } \\
\text { Kgm }^{-3}\end{array}$ & $\begin{array}{l}\text { Specific } \\
\text { heat, } \\
\text { (c) } \\
\text { kJkg }^{-1} \mathbf{k}^{-1}\end{array}$ & $\begin{array}{c}\text { Thermal } \\
\text { Conductivity , (K) } \\
\mathbf{J s}^{-1} \mathbf{m}^{-1} \mathbf{k}^{-1}\end{array}$ & 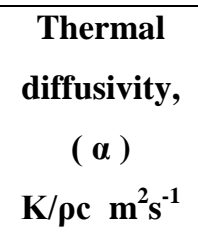 \\
\hline Sand & 1515 & 0.792 & 0.27 & 2.25023E-07 \\
\hline Gravel & 1800 & 0.900 & 0.72 & 4.44444E-07 \\
\hline Basalt & 2150 & 0.840 & $1.7-2.00$ & 9.41307E-07 \\
\hline
\end{tabular}

Thermal diffusivity $(\alpha)$ is a measure of the rapid spread of heat in the material according to Karlekar and Desmond (1982).

\section{Measurements:-}

\section{Solar Radiation:}

Appley Radio Meter was used to measure solar radiation in $\mathrm{W} / \mathrm{m}^{2}$ incident on the plane of the collector surface, glass surface of the drying chamber. A factor of $8.38 \times 10^{-6} \mathrm{~V} / \mathrm{W} . \mathrm{m}^{2}$ was used to convert the reading of the instrument to Watts. The sensitivity of the device is \pm $8.93 \mu \mathrm{V} / \mathrm{Wm}^{2}$.

\section{Temperature:}

The temperature was measured using thermocouple wires placed in the required measuring points. Thermocouples were used, one to measure ambient air temperature, three thermocouples were placed at the inlet of each storage unit at top in the middle and in the bottom, one to measure exit port in each solar storage unite.

The LM35 series are precision integrated-circuit temperature sensors, whose output voltage is linearly proportional to the Celsius (Centigrade) temperature. LM35 calibrated directly in ${ }^{\circ}$ Celsius (Centigrade), linear + $10.0 \mathrm{mV} /{ }^{\circ} \mathrm{C}$ scale factor, $0.5^{\circ} \mathrm{C}$ accuracy guarantee able (at $+25^{\circ} \mathrm{C}$ ); rated for full $-55^{\circ}$ to $+150^{\circ} \mathrm{C}$ range, nonlinearity only $\pm 1 / 4^{\circ} \mathrm{C}$ typical. 
LabJackU3 HV (High-Voltage) was used to collect data (air, solar storage units ) which, were measured during the experiments.

\section{Methods:-}

Thermal performance of various storage units were studied through the following :-

- The storage materials were tested with three thicknesses (20, 40, and 60 $\mathrm{cm})$ at the same time, to select the best thickness which increase the air temperature. that used in the drying process.

- The all experiments carried out with closed units during daylight and opened in the night.

- The all experiments repeated with opened units during daylight and night.

- The air flow rate during all experiments was $0.075 \mathrm{~m}^{3} / \mathrm{sec}$ according to Mohamed et al (2010).

In sensible heat storage (SHS), thermal energy is stored by raising the temperature of a solid or liquid, utilizing the heat capacity and change in temperature of the material during the process of charging and discharging. The amount of heat stored $\left(Q_{s}\right)$ depends on the specific

heat of the medium, the temperature change and the amount of storage material Bal et al, (2010). The quantity of heat recovered $\left(Q_{r}\right)$ by the storage units was calculated by using the same equation:-

$$
Q=\mathrm{M}^{*} \mathrm{C}_{\mathrm{P}} *\left(\mathrm{~T}_{\mathrm{f}}-\mathrm{T}_{\mathrm{i}}\right)
$$

Where :-

$Q_{s}=$ quantity of heat stored $\left(Q_{s}\right)$

$\mathrm{M}=$ mass of storage material

$\mathrm{C}_{\mathrm{p}}=$ specific heat of storage material

$\left(\mathrm{kJ} / \mathrm{kg} \cdot \mathrm{k}^{\mathrm{o}}\right)$

$\mathrm{T}_{\mathrm{f}}=$ the final temperature of storage material

$\mathrm{T}_{\mathrm{i}}=$ the initial temperature of storage material

Available energy from solar radiation stored in the storage units thus the thermal efficiency was considered storage efficiency of storage $\operatorname{units}\left(\eta_{s}\right)$ :- 


$$
\eta_{s}=\frac{Q_{s}}{I A t} \times 100
$$

Where :-

$$
\begin{aligned}
Q_{s} & =\text { quantity of heat store by storage unit } \\
\mathrm{I} & =\text { solar intensity on horizontal surface } \\
& \left(\mathrm{W} / \mathrm{m}^{2}\right) \\
\text { A } & =\text { surface area of dying chamber } \\
\mathrm{t} & =\text { desired time period }
\end{aligned}
$$

\section{RESULTS AND DISCUSSION}

The results of thermal performance of storage materials represented with two stages. First stage with closed solar energy storage units during daylight and opened during night hours. Second stage with opened solar energy storage units during daylight and night hours. The results obtained in this work can be summarized in the following head lines:-

\section{Useful energy gained by storage materials :-}

The hourly useful energy gained by the solar energy storage units with different storage materials (Basalt, Sand, and Gravel) at three thicknesses $(20,40$ and $60 \mathrm{~cm})$ and solar radiation versus solar time, are shown in figures, (3), (4), and (5) at all storage units are closed during daylight and opened at night hours, and figures, (7), (8), and (9) for storage units are opened in daylight and night. It can be noticed that the hourly useful energy gained by storage materials at three thicknesses (20, 40 and 60 $\mathrm{cm})$ increased gradually until it reaches the maximum values at noon (1-2 $\mathrm{pm})$, and then gradually decreased until ( $3 \mathrm{pm})$, because the intensity of solar radiation became less than that adds heat to the storage units as well as heat lost through units.

The above figures clear that the hourly useful energy gained by the closed storage unit with storage materials at $60 \mathrm{~cm}$ thickness was higher than its in storage units at thicknesses 40 and $20 \mathrm{~cm}$. This is due to the heat transferred into the bulk of storage materials at thickness $60 \mathrm{~cm}$. And the amount of heat stored in the storage units increase according to increasing 
thickness, and the rate of increase higher in the case of closed storage unit than the case of opened storage unit.

The hourly useful energy gained by the solar energy storage units with Basalt, Gravel, and Sand at thickness was $20 \mathrm{~cm}$ and solar radiation versus solar time during day (April 27, 2011), shown in figures (6) and (10) when the all storage units are closed in daylight and opened.

These figures clear that the hourly useful energy gained by the storage units with Basalt, Gravel and Sand at thickness was $20 \mathrm{~cm}$ increased gradually until it reaches the maximum values at noon (1-2), and then gradually decreased until ( $3 \mathrm{pm})$, because the intensity of solar radiation became less than that adds heat to the storage units as well as the heat lost through the units, and its clear that the hourly useful energy gained by the closed storage unit with Basalt at thickness $20 \mathrm{~cm}$ was higher than the storage units with Gravel and Sand.

due to the thermal diffusivity of Basalt higher than in the Gravel and Sand (Table 1), Leading to the rapid diffusivity of heat through the material, Leading to the rapid diffusivity of heat through the material then lost to the passing air through storage unit.

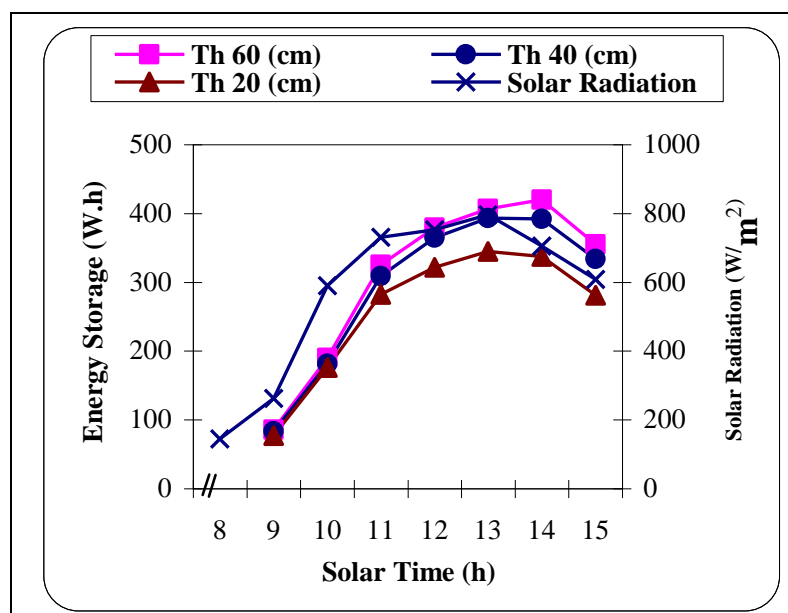

Fig. (3) Hourly solar radiation and energy stored in Basalt in storage units closed during daylight (April $6,2011)$.

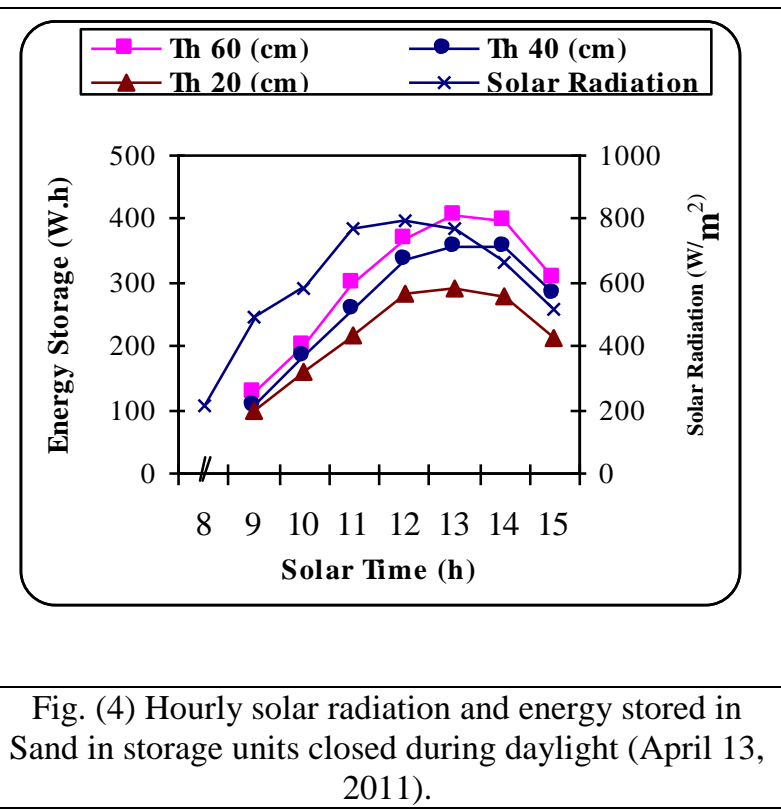

2011). 


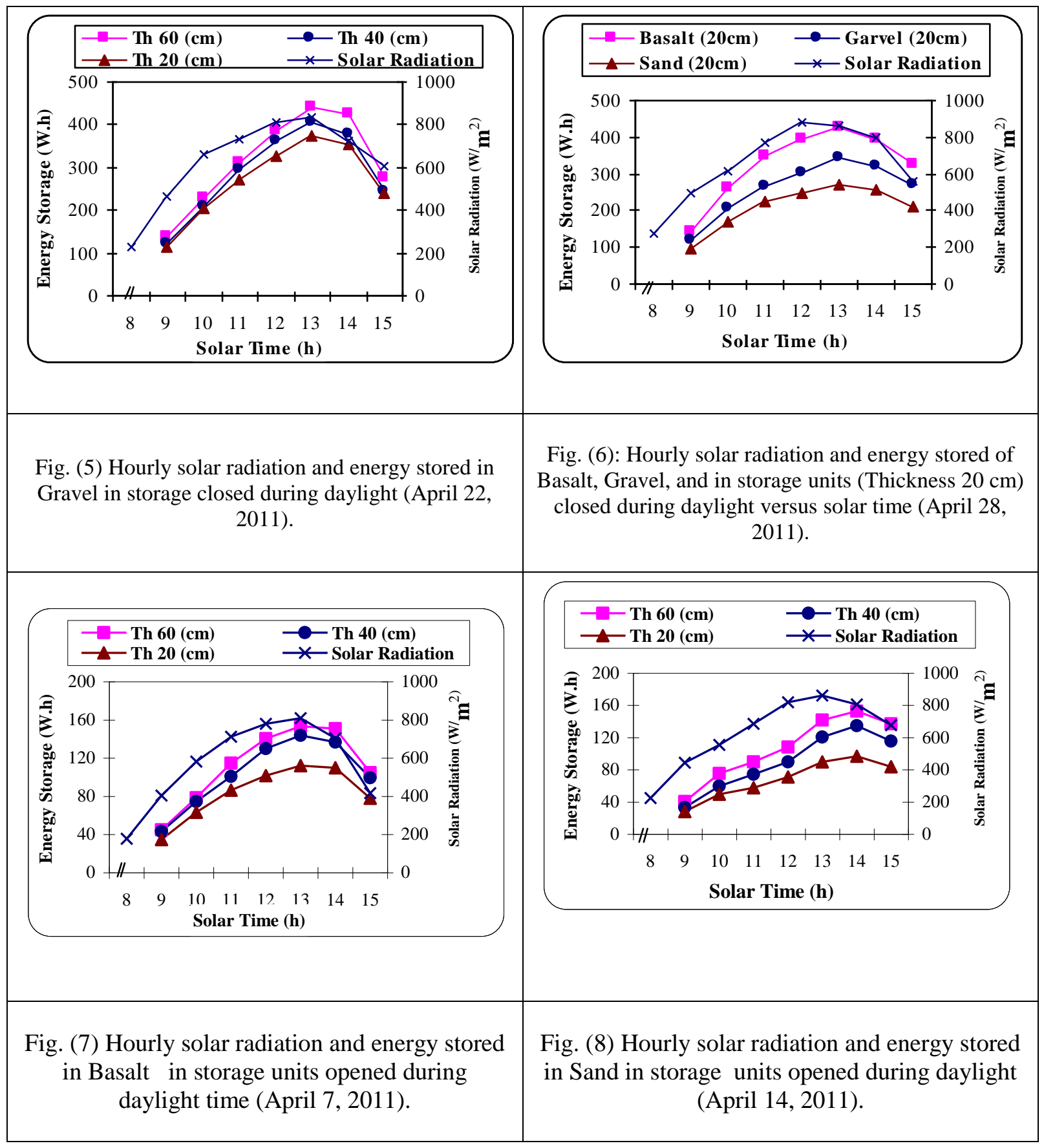

Misr. J. Ag. Eng., Jan 2012 


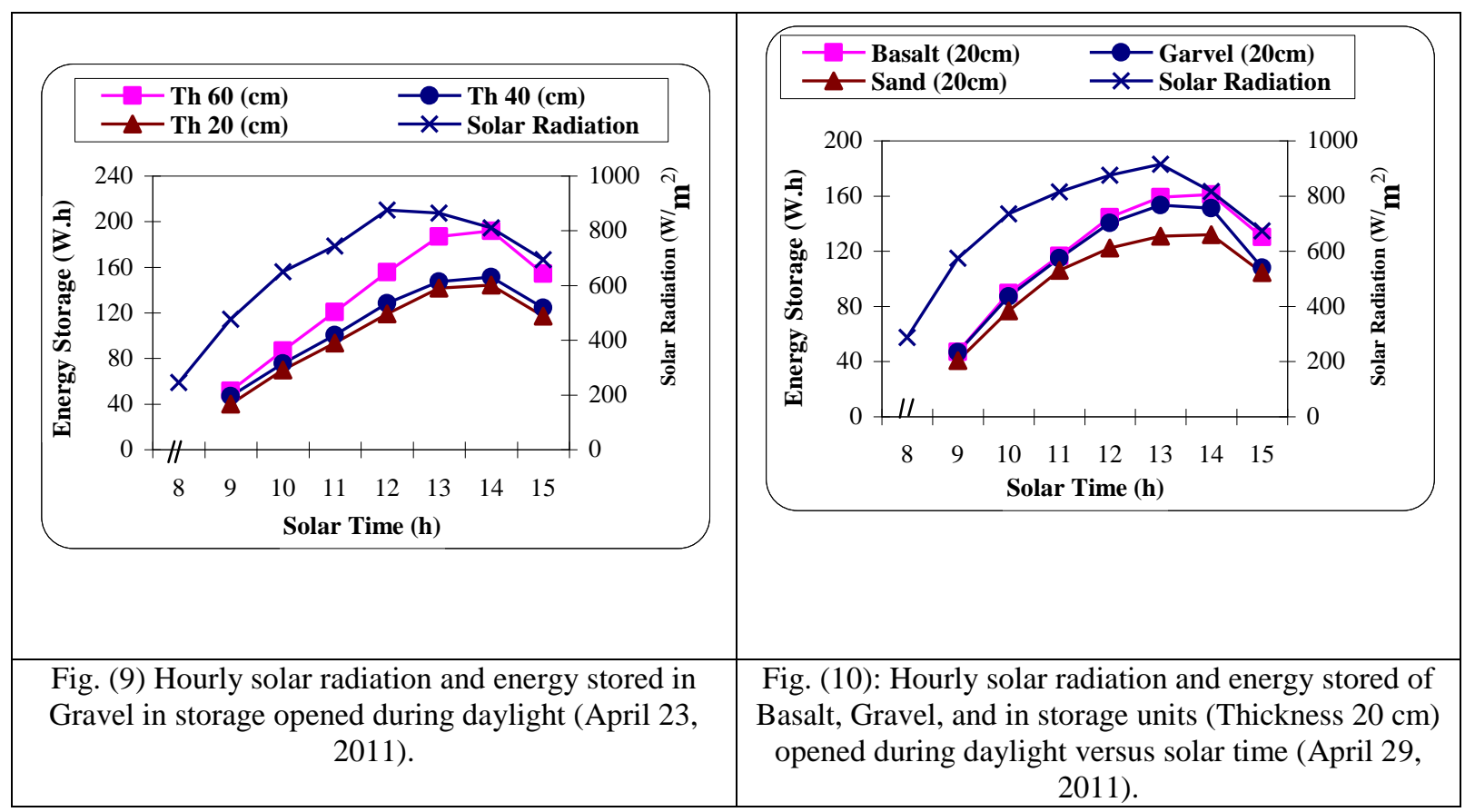

The mean of hourly useful energy gained by closed and opened solar energy storage units with different storage materials (Basalt, Sand, and Gravel) at thicknesses 20,40 and $60 \mathrm{~cm}$ can be presented in the following table:

\begin{tabular}{|c|c|c|c|c|}
\hline \multirow[t]{2}{*}{ Storage material } & \multirow[t]{2}{*}{ condition } & \multicolumn{3}{|c|}{ Energy gained (kw. h) } \\
\hline & & $\begin{array}{c}\text { Th } \\
(20 \mathrm{~cm})\end{array}$ & $\begin{array}{c}\text { Th } \\
(40 \mathrm{~cm})\end{array}$ & $\begin{array}{c}\text { Th } \\
(60 \mathrm{~cm})\end{array}$ \\
\hline \multirow{2}{*}{ Basalt } & closed during daylight & 0.260 & 0.294 & 0.309 \\
\hline & opened during daylight & 0.084 & 0.104 & 0.113 \\
\hline \multirow{2}{*}{ Sand } & closed during daylight & 0.214 & 0.284 & 0.308 \\
\hline & opened during daylight & 0.068 & 0.090 & 0.104 \\
\hline \multirow{2}{*}{ Gravel } & closed during daylight & 0.269 & 0.289 & 0.314 \\
\hline & opened during daylight & 0.104 & 0.111 & 0.135 \\
\hline
\end{tabular}

Non linear regression analysis was applied on the data of closed and opened storage units with storage materials at thicknesses 20, 40, and 60 $\mathrm{cm}$ (, the relationship between energy storage $\left(\mathrm{E}_{\mathrm{S}}\right)$ by w.h and solar radiation (I) by $\mathrm{w} / \mathrm{m}^{2}$ and storage materials thickness $(\mathrm{T})$ by $\mathrm{cm}$ can be represented by the following equation:- 


$$
\mathbf{E}_{\mathbf{s}}=\mathrm{a}^{*} \mathbf{I}^{\mathrm{b}} * \mathbf{T h}^{\mathrm{c}}
$$

Where the values of $\mathrm{R}^{2}$ and constants $\mathrm{a}, \mathrm{b}$, and c can be presented in the following table:

\begin{tabular}{|c|c|c|c|c|c|}
\hline Storage material & condition & a & b & c & R \\
\hline \multirow{2}{*}{ Basalt } & closed during daylight & 1.1587 & 0.7786 & $\mathbf{0 . 1 6 5 1 8}$ & 0.9 \\
\cline { 2 - 6 } & opened during daylight & $\mathbf{0 . 1 7 9 1 5}$ & $\mathbf{0 . 8 3 6 1}$ & $\mathbf{0 . 2 7 4 1}$ & $\mathbf{0 . 9}$ \\
\hline \multirow{2}{*}{ Sand } & closed during daylight & $\mathbf{0 . 3 6 7 8}$ & $\mathbf{0 . 8 5 2 2}$ & $\mathbf{0 . 2 8 6 5}$ & $\mathbf{0 . 9}$ \\
\cline { 2 - 6 } & opened during daylight & $\mathbf{0 . 0 4 0 2 5}$ & $\mathbf{0 . 9 4 5}$ & $\mathbf{0 . 4 1 2 4 4}$ & $\mathbf{0 . 9}$ \\
\hline \multirow{2}{*}{ Gravel } & closed during daylight & $\mathbf{0 . 7 4 0 3}$ & $\mathbf{0 . 8 9 2 4}$ & $\mathbf{1 . 0 0 3 9}$ & $\mathbf{0 . 9}$ \\
\cline { 2 - 6 } & opened during daylight & $\mathbf{0 . 1 1 3 2 7}$ & $\mathbf{0 . 9 2 1 1}$ & $\mathbf{0 . 2 4 7 1 6}$ & $\mathbf{0 . 9}$ \\
\hline
\end{tabular}

\section{Daily useful energy gained by storage materials}

Figures, (11), (12), and (13) show the relationship between the daily (from 8 am until $3 \mathrm{pm}$ ) stored energy per unit of mass in three solar energy storage units with storage materials at three thicknesses were 20, 40 and $60 \mathrm{~cm}$, when the storage units were closed during daylight and opened during daylight these figures clear that the total energy per unit of mass stored in storage unit storage materials at thickness $20 \mathrm{~cm}$ was higher than stored in units at thickness 40 and $60 \mathrm{~cm}$ in the tow cases closed units and opened unit, and values in the case of closed higher than that in the case of opened.

Figure (14) show the relationship between the daily (from 8 am until 3 pm) stored energy per unit of mass in three solar energy storage units with Basalt, Gravel and Sand at thickness was $20 \mathrm{~cm}$, when the storage units were closed during daylight and opened, figure (14) clear that the total energy per unit of mass stored in storage unit with Basalt at thickness 20 $\mathrm{cm}$ was higher than stored in units with Gravel, and Sand in the case closed units, but the reveres in the opened units the total energy per unit of mass stored in storage unit with Sand at thickness $20 \mathrm{~cm}$ was higher than stored in units with Gravel, and Basalt, and values in the case of closed higher than that in the case of open.

The values of daily stored energy per mass unit $(\mathrm{KJ} / \mathrm{Kg}$ ) by closed and opened solar energy storage units with different storage materials (Basalt, Sand, and Gravel) at thicknesses 20, 40 and $60 \mathrm{~cm}$ can be presented in the following table: 
BIOLOGICAL ENGINEERING

\begin{tabular}{|c|c|c|c|c|}
\hline \multirow{2}{*}{ Storage material } & condition & \multicolumn{3}{|c|}{ Daily stored energy $(\mathrm{KJ} / \mathrm{Kg})$} \\
\cline { 3 - 5 } & & $\begin{array}{c}\text { Th } \\
(20 \mathrm{~cm})\end{array}$ & $\begin{array}{c}\text { Th } \\
(40 \mathrm{~cm})\end{array}$ & $\begin{array}{c}\text { Th } \\
(60 \mathrm{~cm})\end{array}$ \\
\hline \multirow{2}{*}{ Basalt } & closed during daylight & 23.98 & 12.88 & 8.89 \\
\cline { 2 - 5 } & opened during daylight & 5.64 & 3.29 & 2.92 \\
\hline \multirow{2}{*}{ Sand } & closed during daylight & 29.02 & 16.73 & 12.31 \\
\cline { 2 - 5 } & opened during daylight & 8.96 & 5.58 & 4.36 \\
\hline \multirow{2}{*}{ Gravel } & closed during daylight & 29.88 & 15.43 & 11.06 \\
\cline { 2 - 5 } & opened during daylight & 11.3 & 8.0 & 4.65 \\
\hline
\end{tabular}

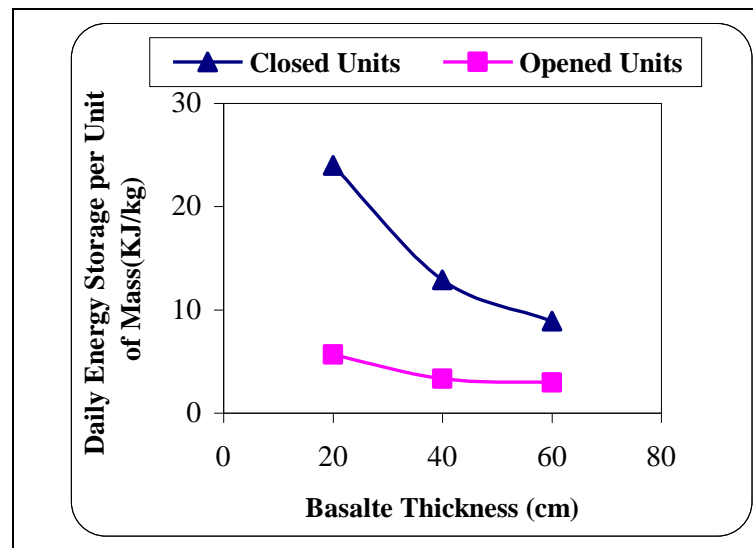

Fig. (11): Daily energy stored per unit of mass in Basalt in storage units closed and opened during daylight versus thickness (April 6-7, 2011).

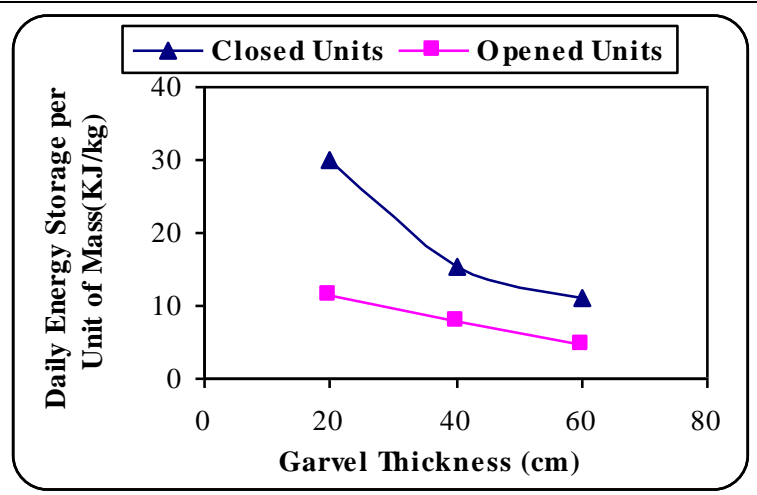

Fig. (13): Daily energy stored per unit of mass in Gravel in storage units closed and opened during daylight versus thickness (April 22-23, 2011).

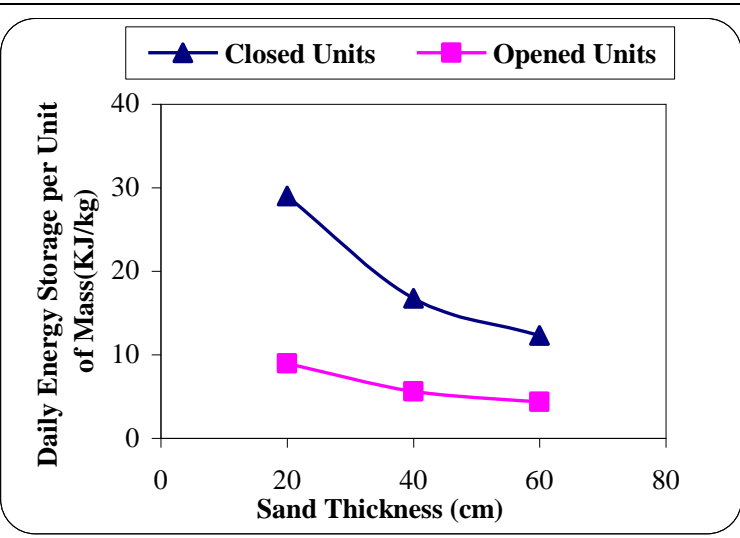

Fig. (12): Daily energy stored per unit of mass in Sand in storage units closed and opened during daylight versus thickness (April 13-14, 2011).

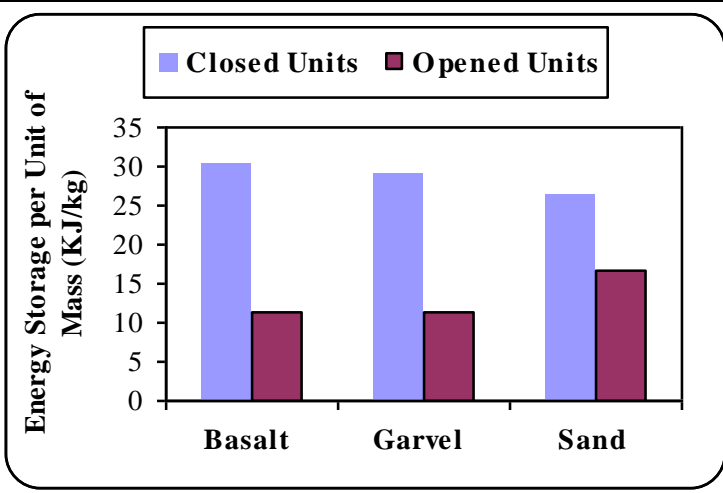

Fig. (14): Daily energy stored in Basalt, Gravel, and Sand in storage units (Thickness $20 \mathrm{~cm}$ ) opened during daylight (April 28-29, 2011). 


\section{Thermal efficiency of storage units:-}

The hourly thermal efficiencies of solar energy storage units with storage materials (Basalt, Sand and Gravel) at three thicknesses (20, 40 and 60 $\mathrm{cm})$ versus solar time, shown in figures, (15), (16), and (17) at the all storage units are closed in daylight and figures, (19), (20), and (21) for storage units are opened in daylight and night. From above figures can be noticed that the hourly thermal efficiencies of solar energy storage units with storage materials at three thicknesses increased gradually until it reaches the maximum values at $(2 \mathrm{pm})$, and then decreased at $(3 \mathrm{pm})$, because the intensity of solar radiation became less than that adds heat to the storage units as well as the heat lost through the units the difference between storage materials temperature in the storage units and ambient temperature was increased so that the heat losses increased which reduces the efficiency. And clear that the hourly thermal efficiencies of closed and opened solar energy storage unit with storage materials at thickness $60 \mathrm{~cm}$ was higher than the storage units at thicknesses 40 and $20 \mathrm{~cm}$. This is due to the heat transferred into the bulk of storage materials at thickness $60 \mathrm{~cm}$.

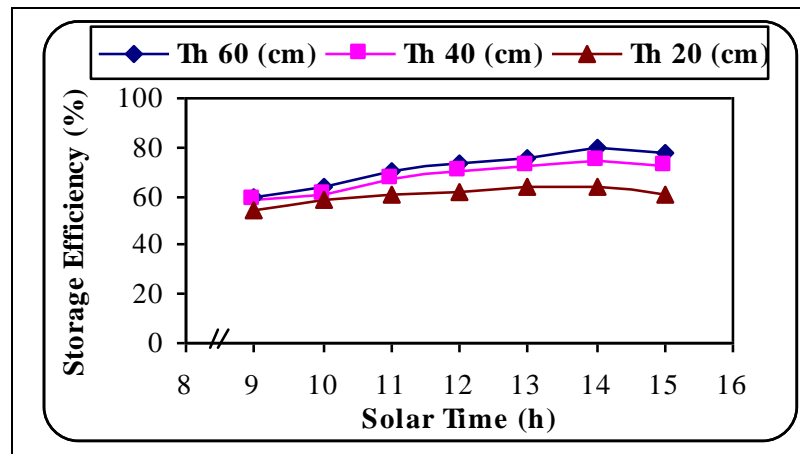

Fig. (15) The hourly thermal efficiencies of storage units with Basalt closed during daylight versus solar time.

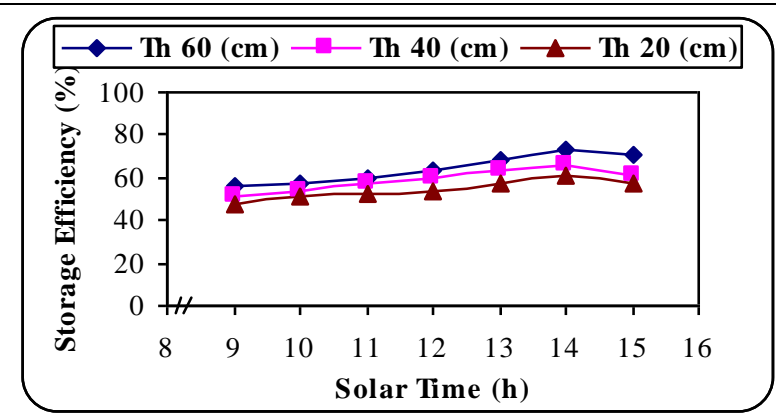

Fig. (17): The hourly thermal efficiencies of storage units with Gravel closed during daylight versus solar

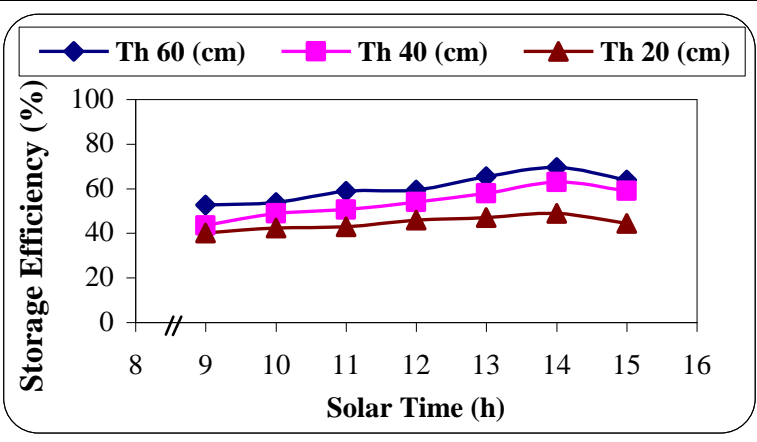

Fig. (16) The hourly thermal efficiencies of storage units with Sand closed during daylight versus solar time .

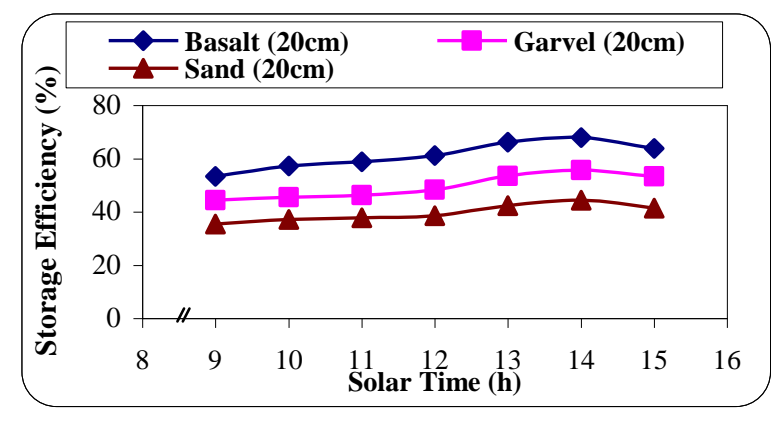

Fig. (18): The hourly thermal efficiencies of storage units with Basalt, Gravel and closed during daylight 


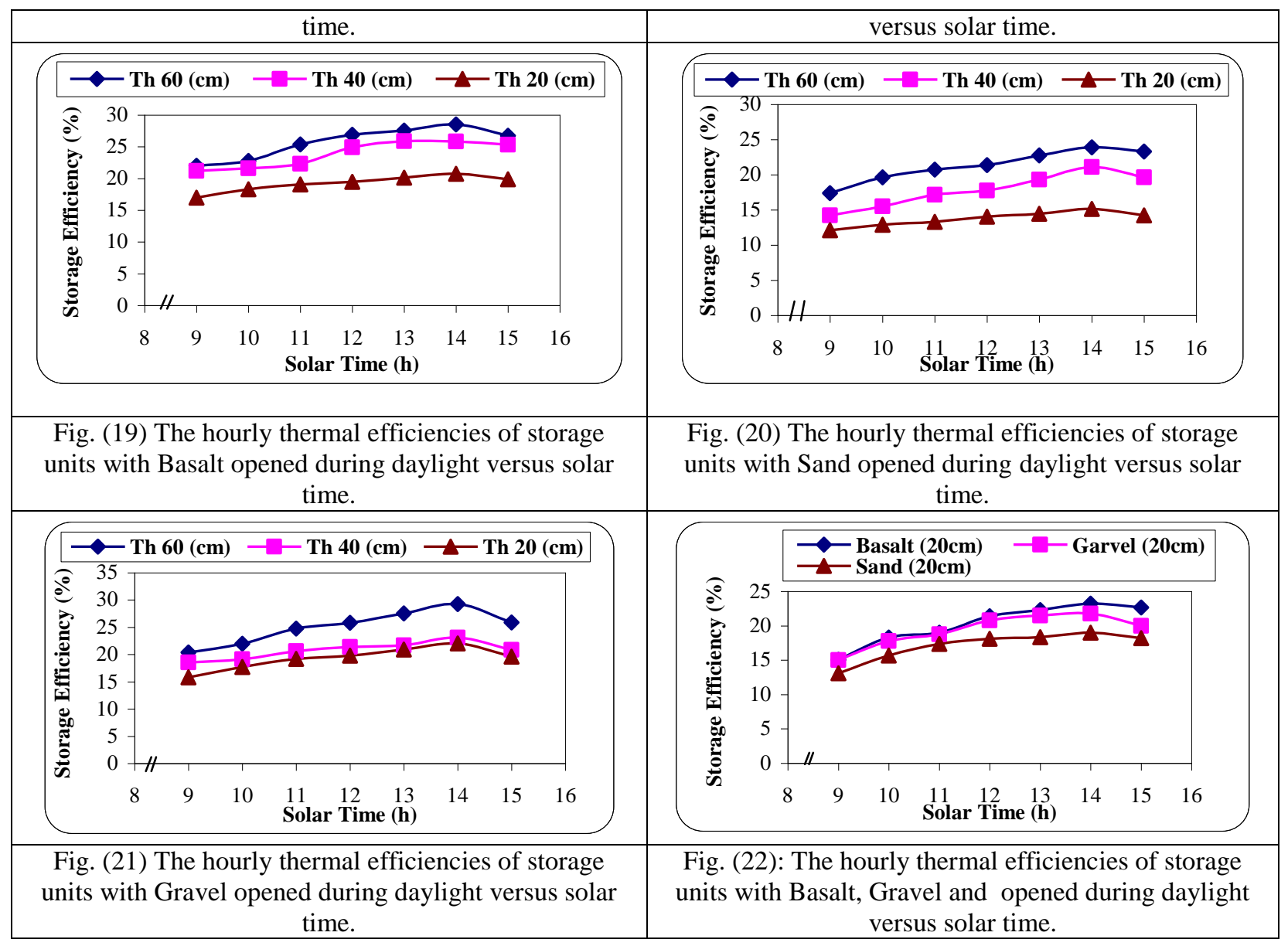

The hourly thermal efficiencies of solar energy storage units with Basalt, Gravel and Sand at thickness was $20 \mathrm{~cm}$ versus solar time, shown in figure (18) when the all storage units are closed and figure (22) for opened. These Figures clear that the hourly thermal efficiencies of closed solar energy storage unit with Basalt at thickness $20 \mathrm{~cm}$ was higher than the storage units with Gravel and Sand at thicknesses $20 \mathrm{~cm}$.

The mean of the hourly thermal efficiencies (\%) of closed and opened solar energy storage units with different storage materials (Basalt, Sand, and Gravel) at thicknesses 20, 40 and $60 \mathrm{~cm}$ can be presented in the following table: 


\begin{tabular}{|c|c|c|c|c|}
\hline \multirow{2}{*}{ Storage material } & \multirow{2}{*}{ condition } & \multicolumn{2}{|c|}{ Mean thermal efficiency $(\%)$} \\
\cline { 3 - 5 } & & $\begin{array}{c}\text { Th } \\
(20 \mathrm{~cm})\end{array}$ & $\begin{array}{c}\text { Th } \\
(40 \mathrm{~cm})\end{array}$ & $\begin{array}{c}\text { Th } \\
(60 \mathrm{~cm})\end{array}$ \\
\hline \multirow{2}{*}{ Basalt } & closed during daylight & 60 & 68 & 71.3 \\
\cline { 2 - 5 } & opened during daylight & 19.24 & 23.86 & 25.69 \\
\hline \multirow{2}{*}{ Sand } & closed during daylight & 44.3 & 58.9 & 63.8 \\
\cline { 2 - 5 } & opened during daylight & 13.7 & 17.81 & 20.79 \\
\hline \multirow{2}{*}{ Gravel } & closed during daylight & 54.5 & 58.6 & 64.1 \\
\cline { 2 - 5 } & opened during daylight & 19.28 & 20.75 & 25.09 \\
\hline
\end{tabular}

\section{The temperature of passing air through storage units:-}

Figures, (23), (24), and (25) show the relationship between ambient temperatures and mean air temperatures passing through solar energy storage units with $0.075 \mathrm{~m}^{3} / \mathrm{sec}$ air flow rate at three thicknesses $(20,40$ and $60 \mathrm{~cm}$ ) versus solar time, after the all storage units are closed in daylight. These figures clear that the mean air temperatures passing through the storage unit with at thickness $20 \mathrm{~cm}$ was higher than its in the storage units at thicknesses 40 and $60 \mathrm{~cm}$ at the beginning of passing air this is because average temperature of storage materials in storage unit at thickness $20 \mathrm{~cm}$ was higher than its in storage units at thicknesses 40 and $60 \mathrm{~cm}$ allowing for greater heat transfer rate from storage unit to the passing air.

Figures, (27), (28), and (29) show the relationship between ambient temperatures and mean temperatures of passing air with $0.075 \mathrm{~m}^{3} / \mathrm{sec}$ air flow rate through solar energy storage units at three thicknesses (20, 40 and $60 \mathrm{~cm}$ ) versus solar time daylight and night hours. These figures clear that the mean temperatures of passing air through the storage unit with at thickness $20 \mathrm{~cm}$ was higher than its in the storage units at thicknesses 40 and $60 \mathrm{~cm}$, and gradually increases until it reaches the maximum value at noon, when the largest intensity of solar radiation, and then gradually decreased.

The maximum difference between entered and the outside air temperature which passing through closed storage units with different storage materials (Basalt, Sand, and Gravel) at thicknesses 20, 40 and $60 \mathrm{~cm}$ 
which occur in the first hours after air passing can be presented in the following table:

\begin{tabular}{|c|c|c|c|}
\hline Storage material & \multicolumn{3}{|c|}{ Maximum difference in temperature $\left({ }^{\circ} \mathrm{C}\right)$} \\
\cline { 2 - 4 } & $\begin{array}{c}\text { Th } \\
(20 \mathrm{~cm})\end{array}$ & $\begin{array}{c}\text { Th } \\
(40 \mathrm{~cm})\end{array}$ & $\begin{array}{c}\text { Th } \\
(60 \mathrm{~cm})\end{array}$ \\
\hline Basalt & 5.53 & 2.51 & 1.3 \\
\hline Sand & 2.55 & 1.37 & 1.05 \\
\hline Gravel & 3.85 & 2.47 & 1.2 \\
\hline
\end{tabular}
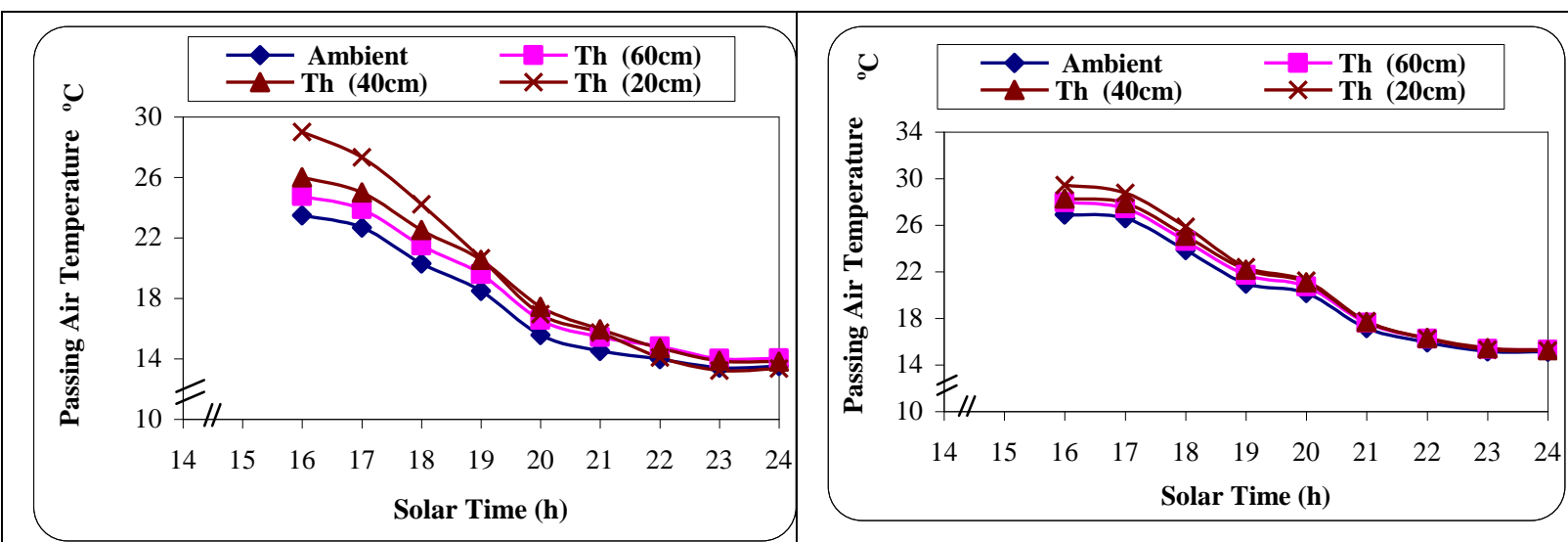

Fig. (23) Mean temperatures of ambient and passing air through storage units with Basalt closed during daylight and opened at night versus solar time.

Fig. (24) Mean temperatures of ambient and passing air through storage units with Sand closed during daylight and opened at night versus solar time.
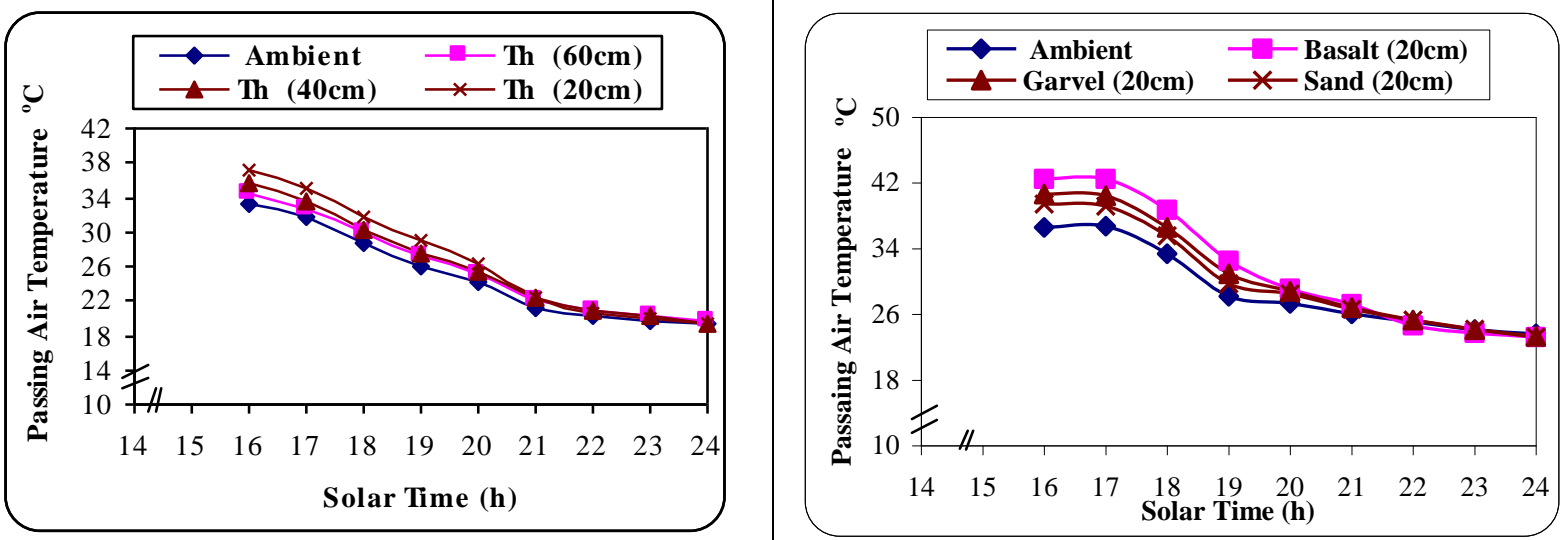

Fig. (25) Mean temperatures of ambient and passing air through storage units with Gravel closed during daylight and opened at night versus solar time.

Fig. (26): Mean temperatures of ambient and passing air through storage units with Basalt, Gravel, and Sand closed during daylight and opened at night versus solar time. 
Figure (26) shows the relationship between ambient temperatures and mean temperatures of passing air with $0.075 \mathrm{~m}^{3} / \mathrm{sec}$ air flow rate through solar energy storage units with Basalt, Gravel and Sand at thickness was $20 \mathrm{~cm}$ versus solar time during night, after its closed during daylight and figure (30) for opened during daylight and night hours. These figures clear that the mean temperatures of air passing through the storage unit with Basalt at thickness $20 \mathrm{~cm}$ was higher than its in the storage units with Gravel and Sand at $20 \mathrm{~cm}$.

The maximum difference between entered and the outside air temperature which passing through opened storage units with different storage materials (Basalt, Sand, and Gravel) at thicknesses 20, 40 and $60 \mathrm{~cm}$ which occur at noon (1-2 pm) can be presented in the following table:

\begin{tabular}{|c|c|c|c|}
\hline Storage material & \multicolumn{3}{|c|}{ Maximum difference in temperature $\left({ }^{\circ} \mathrm{C}\right)$} \\
\cline { 2 - 4 } & $\begin{array}{c}\text { Th } \\
(20 \mathrm{~cm})\end{array}$ & $\begin{array}{c}\text { Th } \\
(40 \mathrm{~cm})\end{array}$ & $\begin{array}{c}\text { Th } \\
(60 \mathrm{~cm})\end{array}$ \\
\hline Basalt & 3.54 & 2.02 & 1.41 \\
\hline Sand & 2.38 & 1.66 & 1.28 \\
\hline Gravel & 2.51 & 1.67 & 1.37 \\
\hline
\end{tabular}

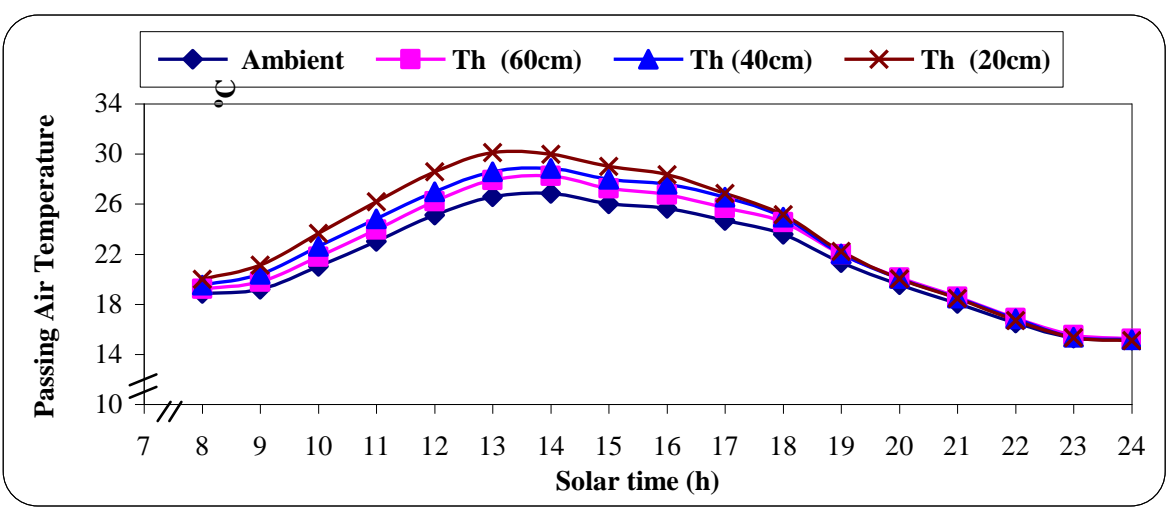

Fig. (27) Mean temperatures of ambient and air passing through storage units with Baslat opened during daylight and at night versus solar time. 


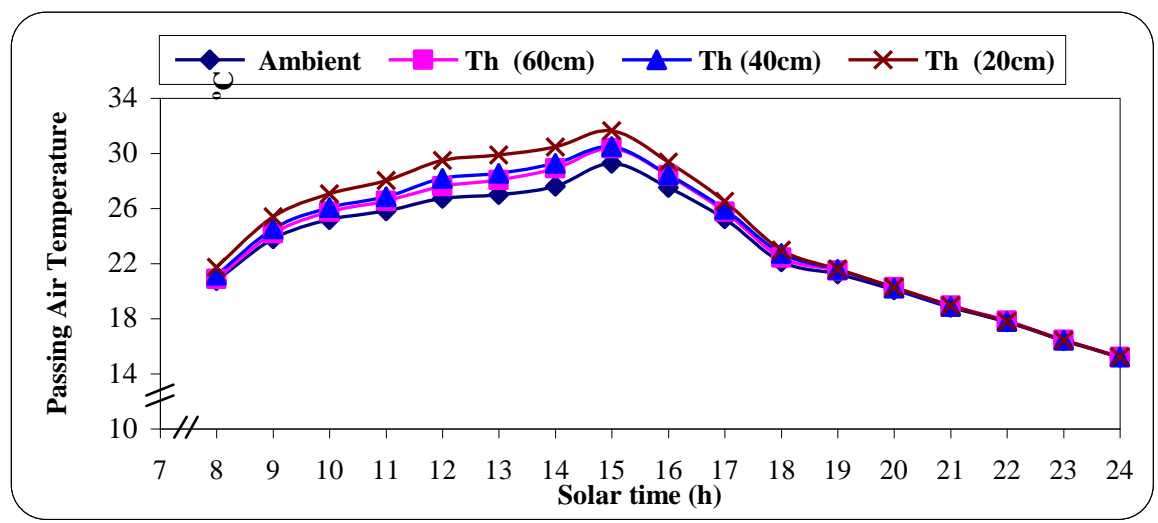

Fig. (28) Mean temperatures of ambient and passing air through storage units with Sand opened during daylight and at night versus solar time.

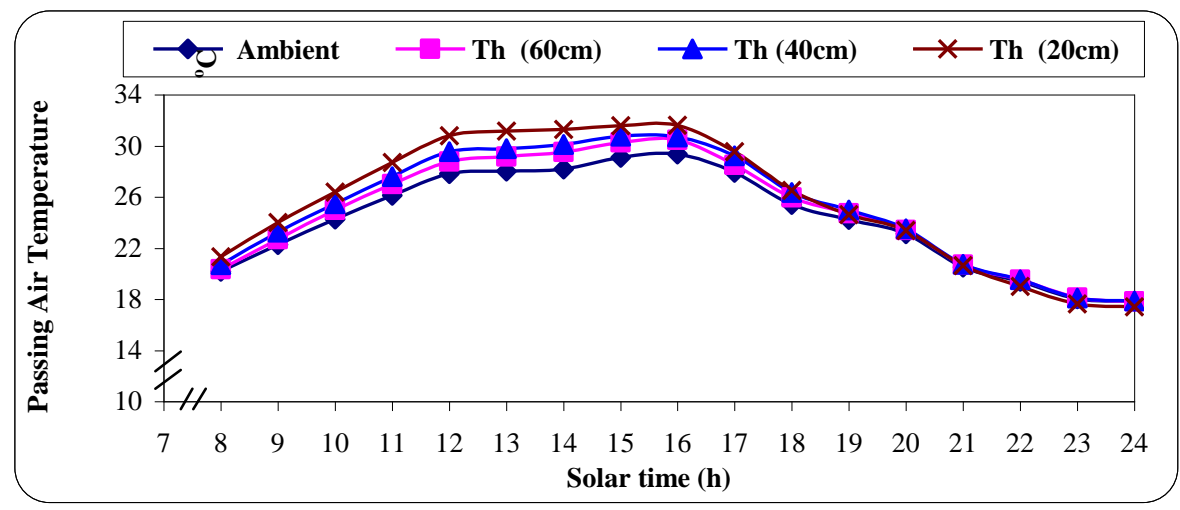

Fig. (29) Mean temperatures of ambient and passing air through storage units with Gravel opened during daylight and at night versus solar time.

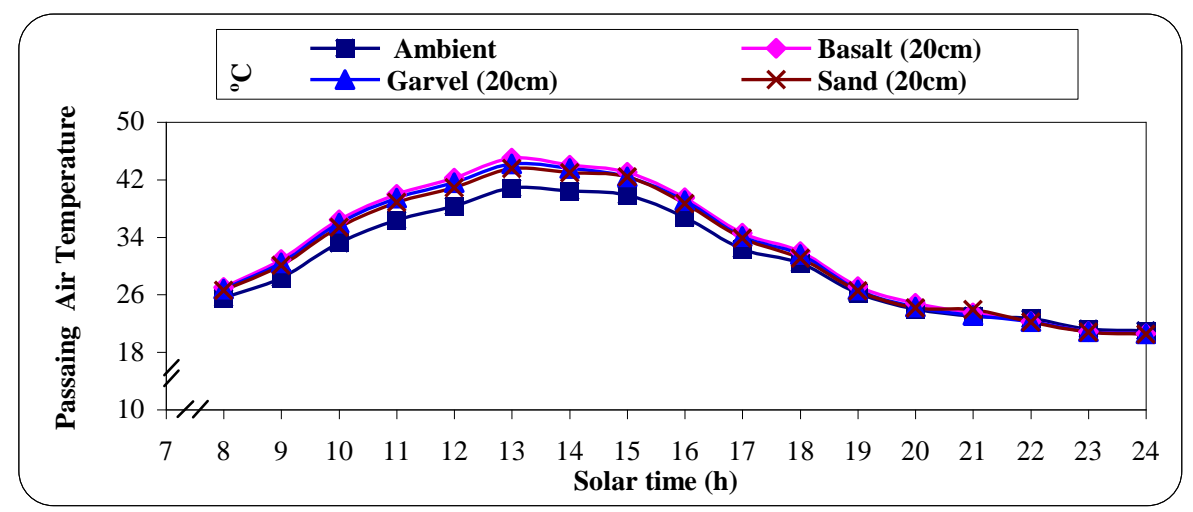

Fig. (30): Mean temperatures of ambient and passing air through storage units with Basalt, Gravel, and Sand (Thickness $20 \mathrm{~cm}$ ) opened during daylight and night versus solar time. 


\section{CONCLUSION:-}

- The amount of hourly heat stored in at thickness $60 \mathrm{~cm}$ was higher than at thicknesses 40 and $20 \mathrm{~cm}$. Basalt gave the best results in with all condition, the amount of hourly heat stored in Basalt at thickness $60 \mathrm{~cm}$ was higher than at thicknesses 40 and $20 \mathrm{~cm}$. by 4.83 and $15.8 \%$ respectively, when the storage units are closed during daylight. And by 7.4 and $25.6 \%$ respectively, when the storage units are open during daylight.

- The daily amount of heat $(\mathrm{kJ} / \mathrm{kg})$ stored in storage materials at thickness $20 \mathrm{~cm}$ was higher than at thicknesses 40 and $60 \mathrm{~cm}$.

- The mean storage efficiency for storage materials at thickness $60 \mathrm{~cm}$ was higher than at thicknesses 40 and $20 \mathrm{~cm}$.

- The difference between air temperature at the entry and exit from the storage units with different storage materials was the highest in the case of air passing through storage unit at $20 \mathrm{~cm}$, when air passing thought storage units after its closed during daylight and opened daylight and night. And for Basalt than Gravel and sand.

\section{REFERENCES}

Abdellatif, S. M., (1985) "Solar energy collection, storage and utilization in protected cropping". Ph. D. Wye College, University of London, UK.

Bal, M.L.; S. Satya.; and S.N. Naik., (2010) " Solar dryer with thermal energy storage systems for drying agricultural food products: A review". Renewable and Sustainable Energy Reviews, 14.; 22982314.

Dincer, I. and S. Dost., (1996) "A perspective on thermal energy storage systems for solar energy applications". International journal of energy research, vol. 20,547-557.

Dincer, I. and A. M. Rosen., (2010) thermal energy storage systems and applications, John Wiley \& Sons, Ltd. United Kingdom.

Duansheng, C.; L. Buzhou.; N. Hemin.; Z. Haishan.; Z. Jiangou.; and T. Quan (1991) "Technology of the energy - saving sunlight greenhouses in China". The proceeding of International Symposium on Applied Technology of Greenhouse, pp:41-49.

Duffie, J. A. and Beckman, W. R., (2006) "Solar Engineering for Thermal Processes". $3^{\text {rd }}$ ed., pp. 907. John Wiley and Sons. New York: USA. 
El-Kassaby, M. M.; and A. A. Ghoneim., (1993) "Comparison of measured and predicted performance of different heat storage systems". Renewable Energy;3(8):849-56.

El-Sebaii A.A .; S. Aboul-Enein.; M.R.I. Ramadan.; and E. El-Bialy., (2007)" Year round performance of double pass solar air heater with packed bed". Energy Conversion and Management 48 .; 990-1003.

Gil, A., M. Medrano., I. Martorell ., A. L. Zaro., P. Dolado., B. Zalba., and L. F. Cabeza (2010) "State of the art on high temperature thermal energy storage for power generation. Part 1Concepts, materials and modellization" . Renewable and Sustainable Energy Reviews 14 .; 31-55.

Hamdan, M. A., (1998) "Investigation of an inexpensive solar collector storage system". Energy Convers Manage;39(5-6):415-20.

Johnson, R. W.; (1992) "Analytical results for specific system. Passive solar buildings. The MIT Pres, Cambridge, Massachusets, London.

Karlekar, B. V.; and R. M. Desmond., (1982). "Engineering Heat Transfer". USA: West Publishing Company.

Mohamed M. A., G. R. Gamea and M. H. Keshek., (2010) "Drying characteristics of okra by different solar dryers". Misr J. Ag. Eng. Vol. 27( 1) :294 - 312.

Ozturk H. H.; and A. Bascetincelik., (2003) "Energy and exergy efficiency of a packed bed heat storage unit for greenhouse heating". Biosyst Eng;86(2):231-45.

Somerton., H.W., (1992) Thermal Properties and Temperature-Related Behavior of Rock/Fluid Systems. Elsevier Publishing Company.

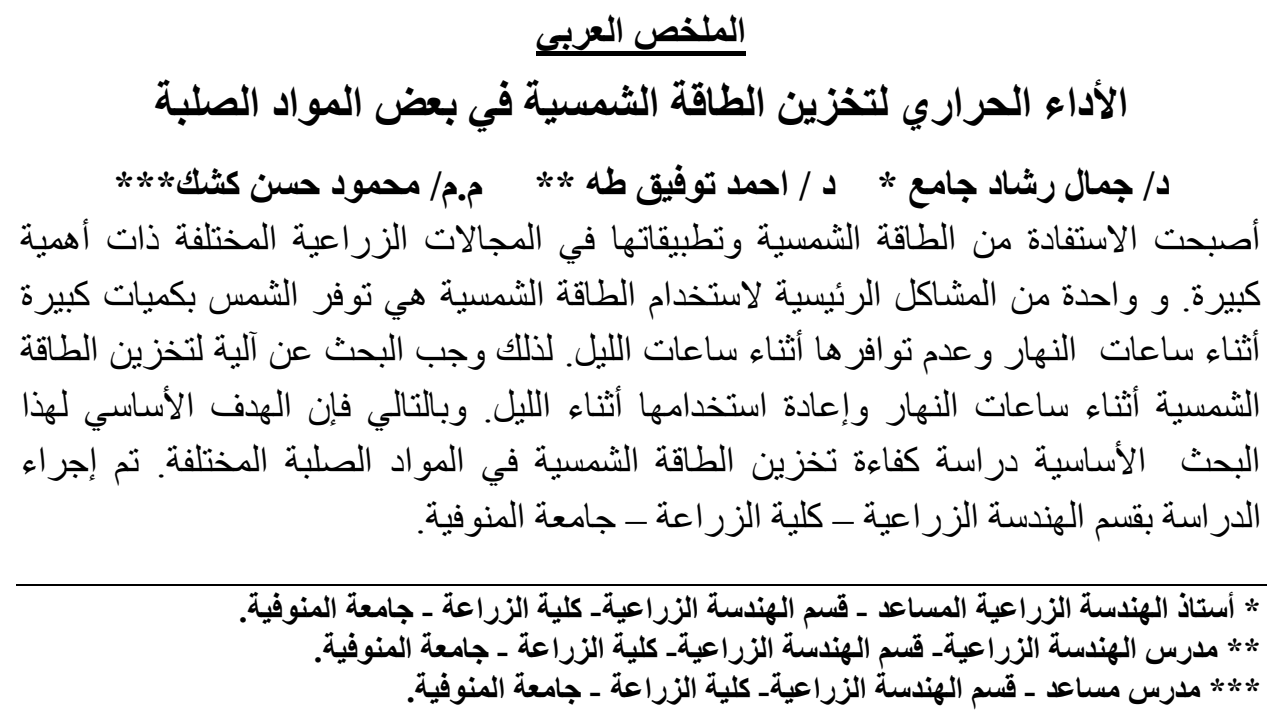


ا ـ تصنيع ثلاث وحدات منشابهة للتخزين الطاقة الثمسية باستخدام ثلاثة أنواع من الصخور.

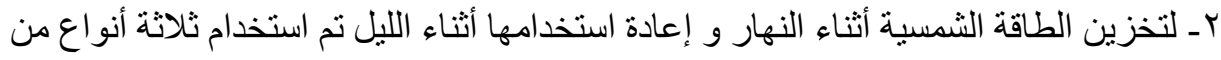

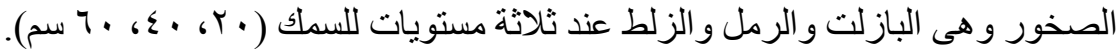
r- در اسة كمية الطاقة الثمسية المخزنة لكل ساعة ، كمية الطاقة الثمسية المخزنة خلازل اليوم لكل كجم من مادة التخزين ، الكفاعة الحرارية لتخزين الطاقة الشمسية في وحدات التخزين، خو اص الهواء المار خلال وحدات التخزين المختلفة.

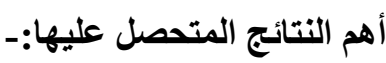

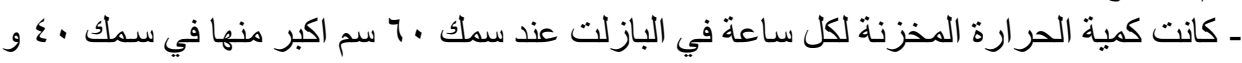

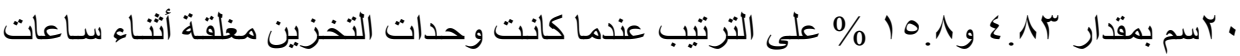

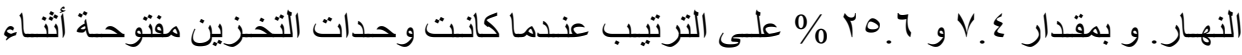
ساعات النهار.

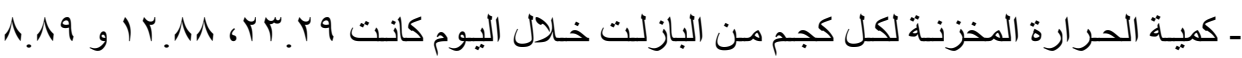

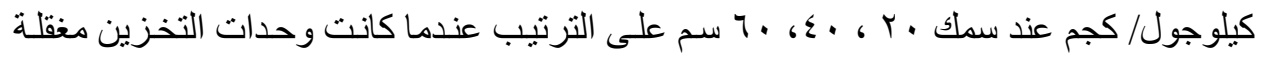

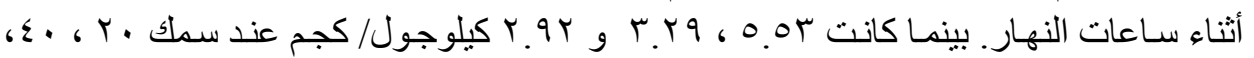

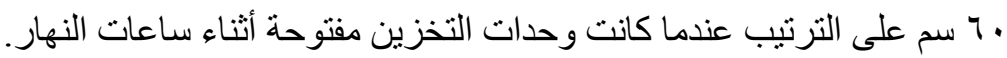

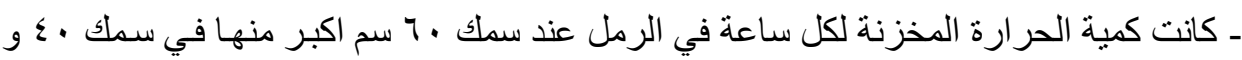

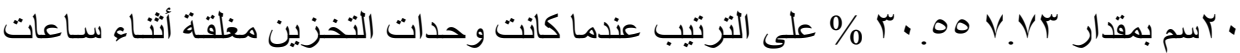

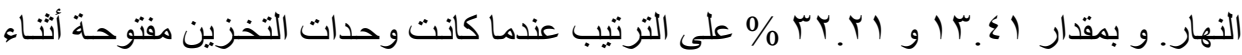
ساعات النهار.

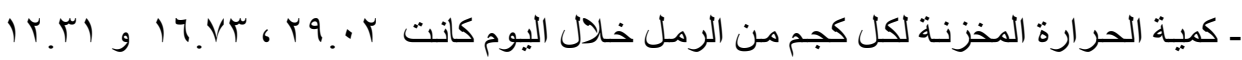

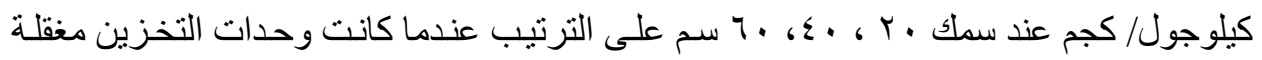

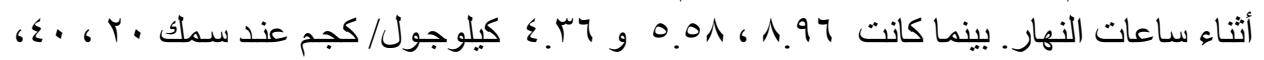

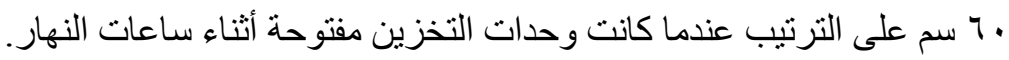

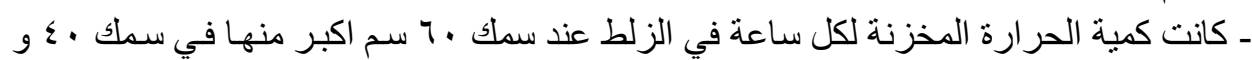

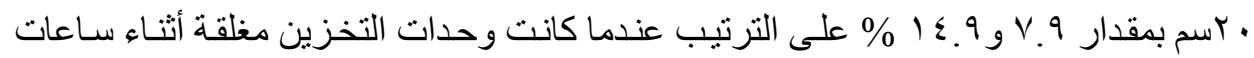

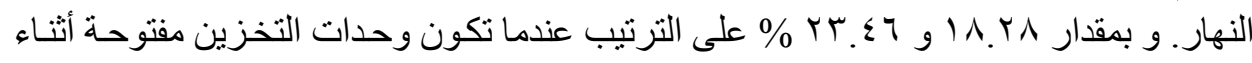
ساعات النهار.

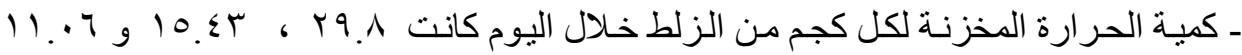

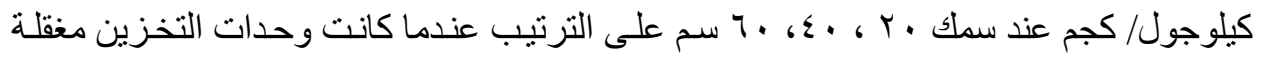

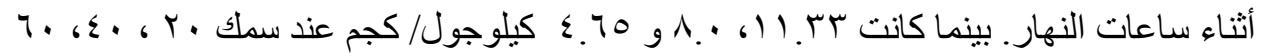

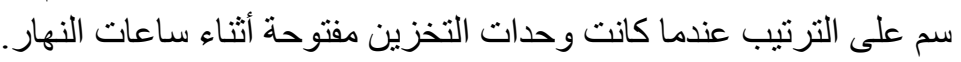
ـ أعطى سمك . 7 سم أعلى كفاءة في تخزين الطاقة الشمسية عند استخدام جميع مواد التخزين.

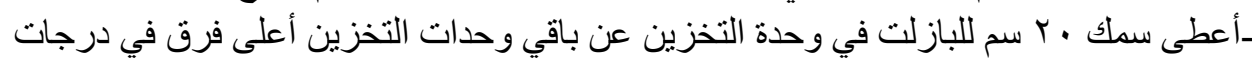

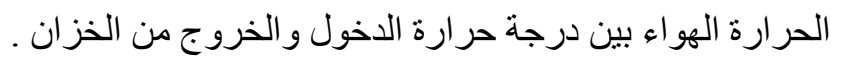

